\title{
Volatile Profile Characterization of Commercial Peach (Prunus persica) Cultivars Grown in Georgia, USA
}

\author{
Jamal Mohammed ${ }^{1}$, Catherine E. Belisle ${ }^{1}$, Shangci Wang ${ }^{2}$, Rachel A. Itle ${ }^{1}$, Koushik Adhikari ${ }^{2} \mathbb{}$ \\ and Dario J. Chavez ${ }^{1,3, *(1)}$ \\ 1 Department of Horticulture, University of Georgia, Griffin, GA 30223, USA; \\ Jamal.Mohammed@uga.edu (J.M.); cbelisle1@ufl.edu (C.E.B.); ritle@uga.edu (R.A.I.) \\ 2 Department of Food Science and Technology, University of Georgia, Griffin, GA 30223, USA; \\ wangsc727@gmail.com (S.W.); koushik7@uga.edu (K.A.) \\ 3 Institute of Plant Breeding Genetics and Genomics, University of Georgia, Athens, GA 30602, USA \\ * Correspondence: dchavez@uga.edu
}

check for updates

Citation: Mohammed, J.; Belisle, C.E.; Wang, S.; Itle, R.A.; Adhikari, K.; Chavez, D.J. Volatile Profile

Characterization of Commercial Peach (Prunus persica) Cultivars Grown in Georgia, USA. Horticulturae 2021, 7, 516. https://doi.org/10.3390/ horticulturae7120516

Academic Editor: Ángel

Calín-Sánchez

Received: 20 October 2021

Accepted: 16 November 2021

Published: 23 November 2021

Publisher's Note: MDPI stays neutral with regard to jurisdictional claims in published maps and institutional affiliations.

Copyright: (c) 2021 by the authors. Licensee MDPI, Basel, Switzerland. This article is an open access article distributed under the terms and conditions of the Creative Commons Attribution (CC BY) license (https:/ / creativecommons.org/licenses/by/ $4.0 /)$.
Abstract: Peach production in Georgia, USA, extends from mid-May to mid-August. Multiple cultivars are commercially grown in the U.S., and each cultivar has unique fruit quality characteristics, which could influence consumer perception and acceptability. Among those, peach flavor has been minimally characterized among cultivars. Headspace-solid phase microextraction (HS-SPME) combined with gas chromatography-mass spectrometry (GC-MS) was used to characterize the volatile profile of 42 peach cultivars commercially grown in 2016. The goal of this research was to understand the aroma composition and content of peach cultivars grown in Georgia, USA. Thirty-six volatile compounds were identified. Significant differences $(p \leq 0.0001)$ were observed for all the flavor volatiles across all cultivars being evaluated. Esters were the major compounds isolated from the 42 peach cultivars, followed by lactones, alcohols, aldehydes, and terpenoids, in that order. Lactones, benzaldehyde, and linalool, which are known to be peach aroma compounds, exhibited the highest mean concentrations among the cultivars with $\gamma$-and $\delta$-decalactones having a concentration of approximately $180 \mathrm{ng} \cdot \mathrm{g}^{-1}$ and $60 \mathrm{ng} \cdot \mathrm{g}^{-1}$, respectively. Among the cultivars, "Majestic" had the highest mean concentration of $\gamma$-decalactone, followed by "Southern Pearl" with approximately $503 \mathrm{ng} \cdot \mathrm{g}^{-1}$ and $443 \mathrm{ng} \cdot \mathrm{g}^{-1}$, respectively. "Southern Pearl" and "Fairtime" also exhibited the highest average concentration of $\delta$-decalactone. The results obtained will help provide an understanding of the distribution of the various volatile organic compounds found in Georgia-grown peach cultivars.

Keywords: flavor; VOCs; Prunus persica; fruit quality; HS-SPME; GC-MS

\section{Introduction}

Fruit quality is a complex trait. Consumers are known to initially evaluate fruit at the point-of-sale by its appearance and later by its flavor and mouth-feel [1]. The appearance will determine the initial purchase, while tasting would define the return buy. Appearance is mostly based on the fruit size and color, while tasting encompasses a combination of factors such as aroma, texture, and sugar/acid ratios [1]. Aroma, fruit firmness, and color are among the most important components that contribute to peach fruit quality [2].

Fruit aroma is produced by emissions of volatile or gaseous compounds and is characterized by the volatile organic compounds' (VOCs) composition. Overall fruit flavor results from the combination of VOCs, sugars, and organic acids. The relative contributions of specific aroma VOCs to the flavor of peaches have been studied by several authors with over 100 VOCs identified [3-5]. Among these volatiles, aldehydes, alcohols, terpenoids, ketones, lactones, carboxylic acids, and esters have been reported [6]. Horvat and Chapman [7] identified $\gamma$-decalactone to be a major contributor of "peach" aroma. Other lactones such as $\gamma$-octalactone, $\gamma$-dodecalactone, $\delta$-decalactone, and 6-pentyl- $\alpha$-pyrone have been also reported to be part of peach aroma, exhibiting a "fruity" or "coconut"-like aroma [7]. 
Terpenoids and aldehydes were identified to be minor contributors [8]. Spencer et al. [9] studied the relationship between the relative VOCs' concentration and sensory attributes in peach. The authors reported a higher concentration of monoterpenes and esters as compared to lactones. However, when considering the detection thresholds of volatiles, lactones were a major contributor to peach aroma.

VOCs' composition changes with fruit ripening. In peach, immature fruit have been reported to be abundant in $\mathrm{C} 6$ compounds such as alcohols and aldehydes. At full maturity, the concentrations of lactones, linalool, and benzaldehyde are known to increase as the $\mathrm{C} 6$ compounds decrease $[10,11]$. Similarly, other studies have been carried out to investigate how different cultural management practices such as fertilization, bagging, and postharvest treatments influence the VOC composition in peaches [12]. Flavor volatile composition is also known to be dependent on the cultivar analyzed. In a study conducted by Robertson et al. [13], the amount of linalool found in white-fleshed peaches was more than that of yellow-fleshed peaches.

The aim of this study was to survey and characterize the VOCs' composition of 42 peach cultivars grown in Georgia, USA. Our hypothesis was that each cultivar has different volatile profiles and their VOCs' composition will change as the ripening season changes. The study was focused on the volatile composition among the peach cultivars grown in Georgia, which were minimally characterized for flavor volatiles.

\section{Materials and Methods}

\subsection{Plant Materials}

A total of 42 peach (Prunus persica L. Batsch) cultivars representing the marketing window of Georgia's production were characterized for their VOC composition (Table 1). Peaches were harvested from 14 May to 29 July in 2016, separating cultivars by early-, mid-, and late-season. Cultivars were commercially grown and managed using the southeastern peach, nectarine, and plum pest management and culture guide [14]. Handling and grading of samples followed commercial procedures from peach growers in Fort Valley, GA, USA. The goal was to obtain peach samples representative of fresh fruit sold in produce markets. A detailed description of this procedure was described by Belisle et al. [15]. After harvesting and grading, samples were kept at $7-10^{\circ} \mathrm{C}$ in commercial boxes at grower locations for $1-3$ days and then transported to Griffin, GA. Here, samples were kept at $4{ }^{\circ} \mathrm{C}$ for 3 days.

\subsection{Sample Preparation}

Before processing, samples were brought to room temperature for 2 to 3 days to allow the fruit to ripen. Throughout ripening, all bruised and damaged peaches were removed frequently to avoid uneven ripening or damaging of other fruit. Ripened fruit was then used and prepared for volatile analysis as follows. Two-gram samples, including the flesh and skin from multiple peaches $(n=5)$, were then weighed into a twenty-milliliter screw cap vial and homogenized using a spatula. A $10 \mu \mathrm{L}$ amount of a $0.045 \mathrm{mg} \mathrm{mL}^{-1}$ internal standard 1-3-dichlorobenzene (Sigma-Alrich, St. Louis, MO, USA) was added to the purée. Three samples per cultivar were analyzed. The extraction procedure that was carried out was adapted from Bacvonkrlj et al. [11]. Solid-phase microextraction (SPME) and gas chromatography coupled with mass spectrometry (GC-MS) were used to evaluate the volatile compounds' composition of each peach cultivar. 
Table 1. List of the 42 peach cultivars and their characteristics, grown in Georgia, United States of America, in 2016.

\begin{tabular}{|c|c|c|c|c|c|c|}
\hline Harvest Season & Cultivar & Flesh Type & Pit Adherence & Flesh Color & Acidity & Harvest Date $^{a}$ \\
\hline \multirow{8}{*}{ Early } & Carored & Melting & Clingstone & Yellow & Standard & 18 May \\
\hline & Fiesta Gem & Melting & Clingstone & Yellow & Standard & 22 May \\
\hline & Flavorich & Melting & Clingstone & Yellow & Standard & 14 May \\
\hline & Goldprince & Melting & Clingstone & Yellow & Standard & 26 May \\
\hline & Rubyprince & Melting & Clingstone & Yellow & Standard & 27 May \\
\hline & Springflame & Nonmelting & Clingstone & Yellow & Standard & 19 May \\
\hline & Springprince & Nonmelting & Clingstone & Yellow & Standard & 18 May \\
\hline & Zee Diamond & Nonmelting & Clingstone & Yellow & Standard & 18 May \\
\hline \multirow{18}{*}{ Mid } & Blazeprince & Melting & Freestone & Yellow & Standard & 14 June \\
\hline & Caroking & Melting & Semifreestone & Yellow & Standard & 15 June \\
\hline & Early Elberta & Melting & Freestone & Yellow & Standard & 23 June \\
\hline & Encore & Melting & Freestone & Yellow & Standard & 23 June \\
\hline & Fireprince & Melting & Freestone & Yellow & Standard & 23 June \\
\hline & Gala & Melting & Semifreestone & Yellow & Standard & 2 June \\
\hline & Harvester & Melting & Freestone & Yellow & Standard & 9 June \\
\hline & Junefire & Melting & Freestone & Yellow & Standard & 16 June \\
\hline & Juneprince & Melting & Semifreestone & Yellow & Standard & 1 June \\
\hline & Majestic & Melting & Freestone & Yellow & Standard & 23 June \\
\hline & Rich Lady & Nonmelting & Semifreestone & Yellow & Standard & 9 June \\
\hline & Rich Pride & Nonmelting & Clingstone & Yellow & Standard & 8 June \\
\hline & Scarletprince & Melting & Freestone & Yellow & Standard & 30 June \\
\hline & Sierra Rich & Melting & Freestone & Yellow & Standard & 16 June \\
\hline & Southern Pearl & Melting & Semifreestone & White & Standard & 8 June \\
\hline & Sureprince & Melting & Semifreestone & Yellow & Standard & 2 June \\
\hline & White Lady & Melting & Freestone & White & Low acid & 25 June \\
\hline & Zee Pride & Nonmelting & Clingstone & Yellow & Standard & 1 June \\
\hline \multirow{16}{*}{ Late } & August Lady & Melting & Freestone & Yellow & Standard & 27 July \\
\hline & Augustprince & Melting & Freestone & Yellow & Standard & 12 July \\
\hline & Early August Prince & Melting & Freestone & Yellow & Standard & 12 July \\
\hline & Early Big Red & Melting & Freestone & Yellow & Standard & 20 July \\
\hline & Fairtime & Melting & Freestone & Yellow & Standard & 20 July \\
\hline & Fat Lady & Melting & Freestone & Yellow & Standard & 21 July \\
\hline & Flameprince 27 & Melting & Freestone & Yellow & Standard & 29 July \\
\hline & Flameprince 29 & Melting & Freestone & Yellow & Standard & 29 July \\
\hline & Julyprince & Melting & Freestone & Yellow & Standard & 1 July \\
\hline & O'Henry & Melting & Freestone & Yellow & Standard & 29 July \\
\hline & Elberta & Melting & Freestone & Yellow & Standard & 13 July \\
\hline & Elberta $\# 2^{b}$ & Melting & Freestone & Yellow & Standard & 21 July \\
\hline & Red Globe & Melting & Freestone & Yellow & Standard & 6 July \\
\hline & Ruston Red & Melting & Freestone & Yellow & Standard & 7 July \\
\hline & Summerflame & Melting & Freestone & Yellow & Standard & 14 July \\
\hline & Summerflame1 & Melting & Freestone & Yellow & Standard & 14 July \\
\hline
\end{tabular}

${ }^{a}$ Commercial harvest date obtained from the grower in Fort Valley, Georgia, United States of America. ${ }^{\mathrm{b}}$ Part of the Elberta cultivar-end ripening window.

\subsection{Isolation of Volatiles}

A dynamic headspace solid-phase microextraction method was used for the isolation and concentration of the volatile compounds. The sample was first equilibrated in an autosampler (Model GC Sampler 80, Agilent Technologies, Santa Clara, CA, USA) at $60^{\circ} \mathrm{C}$ for $30 \mathrm{~min}$ and agitated at $250 \mathrm{rpm}$ with on and off steps of $5 \mathrm{~s}$ and $2 \mathrm{~s}$, respectively. This step helped to promote absorption from the headspace. An SPME fiber coated with 50/30 $\mu \mathrm{m}$ divinylbenzene/carboxen/polydimethylsiloxane (DVB/CAR/PDMS) was then exposed to the headspace of the sample for $30 \mathrm{~min}$ at $60{ }^{\circ} \mathrm{C}$ for it to adsorb the analytes. After the adsorption process was completed, the fiber was then inserted into the injection port of the gas chromatography-mass spectrometry (GC-MS). The fiber, which had the volatile compounds adsorbed onto its surface, was desorbed into the GC injection port for $5 \mathrm{~min}$ 
at $270{ }^{\circ} \mathrm{C}$ in splitless mode. After each injection of volatiles, the fiber was conditioned at $250^{\circ} \mathrm{C}$ for $20 \mathrm{~min}$.

\subsection{GC-MS Analysis}

The individual volatile compounds were analyzed using gas chromatography coupled with a mass spectrometer (Model 7890A, Agilent Technologies, Santa Clara, CA, USA), equipped with a $30 \mathrm{~m} \times 250 \mu \mathrm{m}$ i.d. $\times 0.25 \mu \mathrm{m}$ film thickness HP-5MS column and a mass spectrometer (MS) detector (Model 5977A, Agilent Technologies, Santa Clara, CA, USA). The analysis was performed in splitless mode, and helium was used as the carrier gas

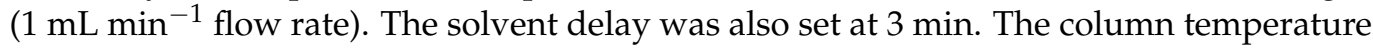
program was as follows: initially, the column was maintained at $40{ }^{\circ} \mathrm{C}$ for $3 \mathrm{~min}$, then programmed at $5^{\circ} \mathrm{C} \mathrm{min}-1$ to $175{ }^{\circ} \mathrm{C}$ and held for $1 \mathrm{~min}$, followed by $10^{\circ} \mathrm{C} \mathrm{min}-1$ to $275^{\circ} \mathrm{C}$, then held for $3 \mathrm{~min}$ with a total run time of $44 \mathrm{~min}$. The mass spectrometer detector was operated in electron impact ionization mode $(70 \mathrm{eV})$ by scanning a mass-to-charge ratio $\left(\mathrm{m} \mathrm{z}^{-1}\right)$ from $50 \mathrm{Da}$ to $400 \mathrm{Da}$ with a scan speed of $1.562 \mu \mathrm{s}^{-1}$.

\subsection{Identification of Volatile Compounds}

For the identification of the compounds, a series of n-alkanes or hydrocarbon standard solution (C7-C30) (SUPELCO, Bellefonte, PA, USA) with an initial concentration of $1000 \mu \mathrm{g} \mathrm{mL}^{-1}$ in hexane was also initially injected and run by the GC-MS under the same conditions. These hydrocarbons' standard solution was diluted in a series of steps (adding $100 \mu \mathrm{L}$ of the concentrated $1000 \mu \mathrm{g} \mathrm{mL}^{-1}$ standard solution to $1 \mathrm{~mL}$ of hexane, then adding $100 \mu \mathrm{L}$ of the previously made solution to $1 \mathrm{~mL}$ methanol and, finally, $250 \mu \mathrm{L}$ of this to $500 \mu \mathrm{L}$ of distilled water) to obtain a working solution that was made up of $250 \mu \mathrm{L}$ of the standard solution in $500 \mu \mathrm{L}$ of distilled water.

The volatile compounds were identified by comparing their mass spectra with the commercially available mass spectra database [National Institute of Standards and Technology (NIST) mass spectral library, Version 2.2, 2014] and by matching their calculated retention indices with the retention indices found in the literature (NIST spectra library collection). In addition, for all the identified compounds, semiquantification was performed to determine their relative concentrations using the peak area of the internal standard (IS).

\subsection{Data Analysis}

Analyses of variance (ANOVAs) were performed in SAS Software Version 9.2 (SAS Institute Inc., Cary, NC, USA) to examine differences among cultivars for the various volatile compounds. Differences among cultivars per volatile compound were examined using the Tukey honestly significant difference (HSD) test with a confidence level of $95 \%$. Principal component analysis (PCA) was performed on the data using JMP software Version 14.0 (SAS Institute Inc., Cary, NC, USA) to detect group clustering formation and establish relations among samples and volatile compounds in 2016.

\section{Results and Discussion}

\subsection{Identification of Volatile Compounds}

The Supplementary Information (Table S1) provides a thorough description of all the volatile compounds detected per cultivar with their individual concentrations. A total of 36 volatile compounds were identified. Comparisons among cultivars were significantly different $(p \leq 0.0001)$ for all compounds. Among these compounds, 6 were aldehydes, 6 alcohols, 10 esters, 8 lactones, 4 terpenoids, 1 carboxylic acid, and 1 ketone (Tables S1 and 2). Among the three harvest seasons, the highest number of the volatiles was detected in the peaches belonging to both the mid- and late-season cultivars (Table 3). A total of 35 volatiles were detected in both mid- and late-season cultivars, except for dodecanal and ethyl octanoate, respectively. A total of 30 volatiles were detected among early-ripening peach cultivars, with benzaldehyde, methyl hexanoate, ethyl octanoate, $\gamma$-octanolactone, $\delta$-octalactone, and $\gamma$-nonalactone not detected. 
The relative total concentration of esters per cultivar was high across all ripening seasons (Figure 1 and Table 3). The relative total concentration of alcohols per cultivar was high in early-ripening cultivars, decreasing in the mid- and late-season cultivars. The relative concentration of lactones per cultivar was high in mid-season cultivars followed by late-season cultivars (Figure 1 and Table 3). Early-season cultivars had the lowest relative concentration of lactones per cultivar. The make-up of the different classes of VOCs per season may suggest that early-season peach cultivars might have more green and grassy notes due to the higher concentrations of alcohols detected, while mid- and late-season cultivars may have an increase of peach-like aromas due to the higher concentrations of lactones.

Table 2. Volatile compounds detected in the fresh fruit of all 42 peach cultivars grown in Georgia, United States of America, in 2016.

\begin{tabular}{|c|c|c|c|c|}
\hline Classification & Volatile Compounds ${ }^{a}$ & Code $^{b}$ & $R I(\operatorname{Exp})^{c}$ & RI (Lit) ${ }^{d}$ \\
\hline \multirow[t]{6}{*}{ Aldehydes } & Hexanal & A1 & 798 & 800 \\
\hline & Benzaldehyde & $\mathrm{A} 2$ & 962 & 961 \\
\hline & Benzeneacetaldehyde & A3 & 1048 & 1049 \\
\hline & Nonanal & A4 & 1108.5 & 1102 \\
\hline & Decanal & A5 & 1211 & 1195 \\
\hline & Dodecanal & A7 & 1413.7 & 1412 \\
\hline \multirow[t]{6}{*}{ Alcohols } & (E)-3-Hexen-1-ol & B1 & 829 & 845 \\
\hline & 2-Hexen-1-ol, (E)- & B2 & 850 & 855 \\
\hline & Hexanol & B3 & 855 & 867 \\
\hline & Octanol & B4 & 1075.3 & 1068 \\
\hline & 1-Nonanol & B5 & 1172.6 & 1172 \\
\hline & 1-Undecanol & B6 & 1371.9 & 1370 \\
\hline \multirow[t]{10}{*}{ Esters } & Methyl hexanoate & E1 & 930 & 924 \\
\hline & 3-Hexen-1-ol, acetate, (Z)- & E2 & 1012 & 1011 \\
\hline & Hexyl acetate & E3 & 1019 & 1010 \\
\hline & 2-Hexen-1-ol, acetate, (Z)- & $\mathrm{E} 4$ & 1022 & 1007 \\
\hline & Methyl benzoate & E5 & 1101.2 & 1106 \\
\hline & Methyl octanoate & E6 & 1126.6 & 1128 \\
\hline & Ethyl octanoate & E7 & 1201.1 & 1190 \\
\hline & 2(E)-Hexenyl butanoate & E8 & 1202 & 1180 \\
\hline & Methyl decanoate & E9 & 1327.6 & 1328 \\
\hline & Methyl dodecanoate & E10 & 1526.3 & 1527 \\
\hline \multirow[t]{8}{*}{ Lactones } & $\gamma$-Hexalactone & L1 & 1061 & 1059 \\
\hline & $\gamma$-Octanolactone & L2 & 1261.7 & 1260 \\
\hline & $\delta$-Octalactone & L3 & 1291.4 & 1308 \\
\hline & $\gamma$-Nonalactone & L4 & 1366.1 & 1363 \\
\hline & 6-Amyl- $\alpha$-pyrone & L5 & 1459.8 & 1465 \\
\hline & $\gamma$-Decalactone & L6 & 1471.7 & 1463 \\
\hline & $\delta$-Decalactone & L7 & 1501.6 & 1496 \\
\hline & $\gamma$-Dodecalactone & L8 & 1681.1 & 1671 \\
\hline \multirow[t]{4}{*}{ Terpenes } & $\beta$-Myrcene & $\mathrm{T} 1$ & 996 & 992 \\
\hline & D-Limonene & $\mathrm{T} 2$ & 1033 & 1028 \\
\hline & Linalool & T3 & 1104.1 & 1104 \\
\hline & Geranyl acetone & $\mathrm{T} 4$ & 1455.8 & 1454 \\
\hline Carboxylic acids & Benzoic acid & BA & 1165.5 & 1162 \\
\hline Ketones & $\beta$-Ionone & K1 & 1492.8 & 1486 \\
\hline
\end{tabular}


Table 3. Volatile compounds (ng. $\mathrm{g}^{-1}$ ) detected in fresh fruit of all 42 peach cultivars grown in Georgia, United States of America, in 2016, as classified by ripening season.

\begin{tabular}{|c|c|c|c|c|c|}
\hline Classification & Volatile Compounds & Code $^{a}$ & Early-Season & Mid-Season & Late-Season \\
\hline \multirow[t]{6}{*}{ Aldehydes } & Hexanal & A1 & $6.1 \mathrm{a}^{\mathrm{b}}$ & $1.1 \mathrm{~b}$ & $3.2 \mathrm{~b}$ \\
\hline & Benzaldehyde & $\mathrm{A} 2$ & $\operatorname{tr}$ & $22.0 \mathrm{~b}$ & $35.9 \mathrm{a}$ \\
\hline & Benzeneacetaldehyde & A3 & $0.9 \mathrm{~b}$ & $0.9 \mathrm{~b}$ & $3.1 \mathrm{a}$ \\
\hline & Nonanal & A4 & $14.5 \mathrm{a}$ & $6.4 \mathrm{~b}$ & $5.5 \mathrm{~b}$ \\
\hline & Decanal & A5 & 1.4 & 1.5 & 1.7 \\
\hline & Dodecanal & A7 & 0.6 & $\operatorname{tr}$ & 0.3 \\
\hline \multirow[t]{6}{*}{ Alcohols } & (E)-3-Hexen-1-ol & B1 & $195.7 \mathrm{a}$ & $37.4 \mathrm{~b}$ & $33.2 \mathrm{~b}$ \\
\hline & 2-Hexen-1-ol, (E)- & B2 & $25.5 \mathrm{ab}$ & $7.5 \mathrm{~b}$ & $49.4 \mathrm{a}$ \\
\hline & Hexanol & B3 & 41.7 & 69.7 & 20.7 \\
\hline & Octanol & B4 & 0.3 & 0.1 & $\operatorname{tr}$ \\
\hline & 1-Nonanol & B5 & $4.2 \mathrm{a}$ & $3.5 \mathrm{a}$ & $2.3 \mathrm{~b}$ \\
\hline & 1-Undecanol & B6 & $23.7 \mathrm{a}$ & $5.4 \mathrm{~b}$ & $7.2 \mathrm{~b}$ \\
\hline \multirow[t]{10}{*}{ Esters } & Methyl hexanoate & E1 & $\operatorname{tr}$ & 0.5 & 0.7 \\
\hline & 3-Hexen-1-ol, acetate, (Z)- & E2 & $37.3 \mathrm{c}$ & $82.1 \mathrm{~b}$ & $125.6 \mathrm{a}$ \\
\hline & Hexyl acetate & E3 & 379.4 & 258.3 & 263.0 \\
\hline & 2-Hexen-1-ol, acetate, (Z)- & E4 & 273.8 & 165.9 & 177.6 \\
\hline & Methyl benzoate & E5 & 0.7 & 1.3 & 0.6 \\
\hline & Methyl octanoate & E6 & $2.1 \mathrm{~b}$ & $5.2 \mathrm{a}$ & $2.6 \mathrm{~b}$ \\
\hline & Ethyl octanoate & E7 & $\operatorname{tr}$ & 5.6 & $\operatorname{tr}$ \\
\hline & 2(E)-Hexenyl butanoate & E8 & $0.4 \mathrm{~b}$ & $0.4 \mathrm{~b}$ & $1.3 \mathrm{a}$ \\
\hline & Methyl decanoate & E9 & 3.6 & 2.5 & 3.0 \\
\hline & Methyl dodecanoate & E10 & 0.7 & 1.6 & 2.0 \\
\hline \multirow[t]{8}{*}{ Lactones } & $\gamma$-Hexalactone & L1 & $4.9 \mathrm{~b}$ & $7.0 \mathrm{a}$ & $4.4 \mathrm{~b}$ \\
\hline & $\gamma$-Octanolactone & $\mathrm{L} 2$ & $\operatorname{tr}$ & $3.6 \mathrm{a}$ & $1.0 \mathrm{~b}$ \\
\hline & $\delta$-Octalactone & L3 & $\operatorname{tr}$ & $0.6 \mathrm{a}$ & $0.1 \mathrm{~b}$ \\
\hline & $\gamma$-Nonalactone & $\mathrm{L} 4$ & $\operatorname{tr}$ & 0.5 & 0.3 \\
\hline & 6-Amyl- $\alpha$-pyrone & L5 & 30.8 & 48.4 & 44.7 \\
\hline & $\gamma$-Decalactone & L6 & $120.6 \mathrm{~b}$ & $228.9 \mathrm{a}$ & $155.5 \mathrm{~b}$ \\
\hline & $\delta$-Decalactone & L7 & 44.0 & 71.0 & 61.6 \\
\hline & $\gamma$-Dodecalactone & L8 & 20.4 & 27.1 & 14.8 \\
\hline \multirow[t]{4}{*}{ Terpenes } & $\beta$-Myrcene & $\mathrm{T} 1$ & 1.3 & 0.4 & 0.5 \\
\hline & D-Limonene & $\mathrm{T} 2$ & 0.9 & 0.8 & 0.6 \\
\hline & Linalool & $\mathrm{T} 3$ & $16.5 \mathrm{a}$ & $5.9 \mathrm{~b}$ & $5.5 \mathrm{~b}$ \\
\hline & Geranyl acetone & $\mathrm{T} 4$ & $1.9 \mathrm{a}$ & $0.1 b$ & $0.7 \mathrm{~b}$ \\
\hline Carboxylic acids & Benzoic acid & $\mathrm{BA}$ & $1.3 \mathrm{~b}$ & $0.4 \mathrm{~b}$ & $4.1 \mathrm{a}$ \\
\hline Ketones & $\beta$-Ionone & K1 & 3.0 & 4.8 & 0.5 \\
\hline
\end{tabular}

${ }^{a}$ A, aldehyde; B, alcohol; E, ester; L, lactone; T, terpenoid; BA, carboxylic acid; K, ketone. The letter plus the number represents the compound corresponding to the code in Table $1 .{ }^{\mathrm{b}}$ Different letters within a row indicate a significant difference between ripening seasons using the LSD test at $p<0.05$. Early-season $n=24$, mid-season $n=48$, and late-season $n=54$. Each cultivar had 3 replicates. tr Traces: minimum quantitative value of $<0.4 \mathrm{ng} \cdot \mathrm{g}^{-1}$.

In this study, the total aldehydes contributed to almost $3.4 \%$ of the total flavor profile (Figure 1). Benzaldehyde (A2) was the dominant aldehyde with over $62 \%$ of the total aldehyde contribution (Figure 2). Alcohols contributed almost $14 \%$ of the total flavor profile (Figure 1) with (E)-3-hexen-1-ol (B1) contributing approximately $43 \%$ of the total relative concentration of alcohols (Figure 3). Esters contributed approximately $52 \%$ of the total volatiles (Figure 1). Overall, esters are known to be contributors of fruity and floral notes in peach [6]. Hexyl acetate (E3) contributed approximately $50 \%$ of the total esters (Figure 4). This may suggest that the peach cultivars used in this study may have had a more fruity and floral smell. Eight lactones contributed almost $27 \%$ of the total volatiles (Figure 1), with $\gamma$-decalactone (L6) as the dominant lactone (Figure 5). This result was consistent with the findings of Wang et al. [6], where $\gamma$-decalactone (L6) and $\delta$-decalactone (L7) were the major components of all lactone compounds identified, with 
both accounting for almost $80 \%$ of all lactones. In our study, $\gamma$-decalactone (L6) and $\delta$ decalactone (L7) accounted for almost $70 \%$ of all lactones. Four terpenoids were identified, and they accounted for approximately $1 \%$ of all the volatiles (Figure 1). Linalool (T3) was the dominant terpenoid and accounted for over $79 \%$ of the total terpenoids. In this work, only one ketone ( $\beta$-ionone-K1) and one carboxylic acid (benzoic acid -BA) were identified (Table 1). The sum of these contributed to about $0.1 \%$ of the total flavor profile per cultivar. Because of their low levels, these are not discussed here in detail.

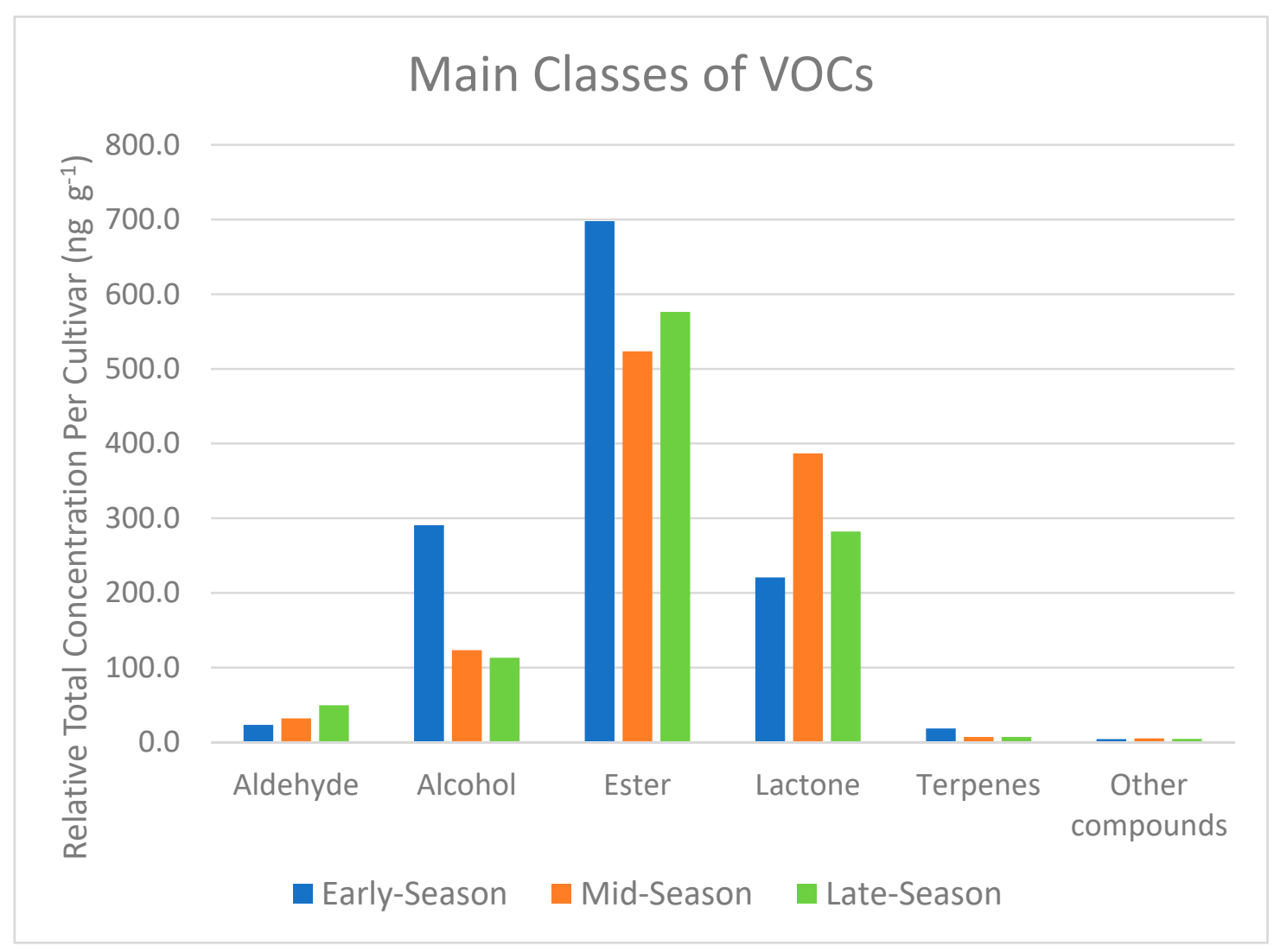

Figure 1. Relative total concentration (ng. $\mathrm{g}^{-1}$ ) per cultivar among the main classes of volatile compounds and across different ripening seasons in peach fruit. Early-season $n=24$, mid-season $n=48$, and late-season $n=54$. Each cultivar was replicated with 3 fruit purée samples.

\subsection{Volatile Compounds' Composition}

VOCs' concentrations were different across cultivars. Table 4 reports the concentration of the major VOCs that are known to be present in peach $[3,7]$. These compounds have been suggested to be prominent at immature (3-hexen-1-ol, acetate, ( $Z$ )-; and 2-hexen1 -ol, acetate, ( $Z$ )-) and mature ( $\gamma$-decalactone, $\delta$-decalactone, $\gamma$-dodecalactone, linalool, benzaldehyde, hexyl acetate and 6-amyl- $\alpha$-pyrone) fruit development and responsible for peach aroma. 
Table 4. Mean content of the major ${ }^{\text {a }}$ volatile compounds $\left(\mathrm{ng} \cdot \mathrm{g}^{-1}\right)$ in 42 fresh peach cultivars grown in Georgia, United States of America, in 2016.

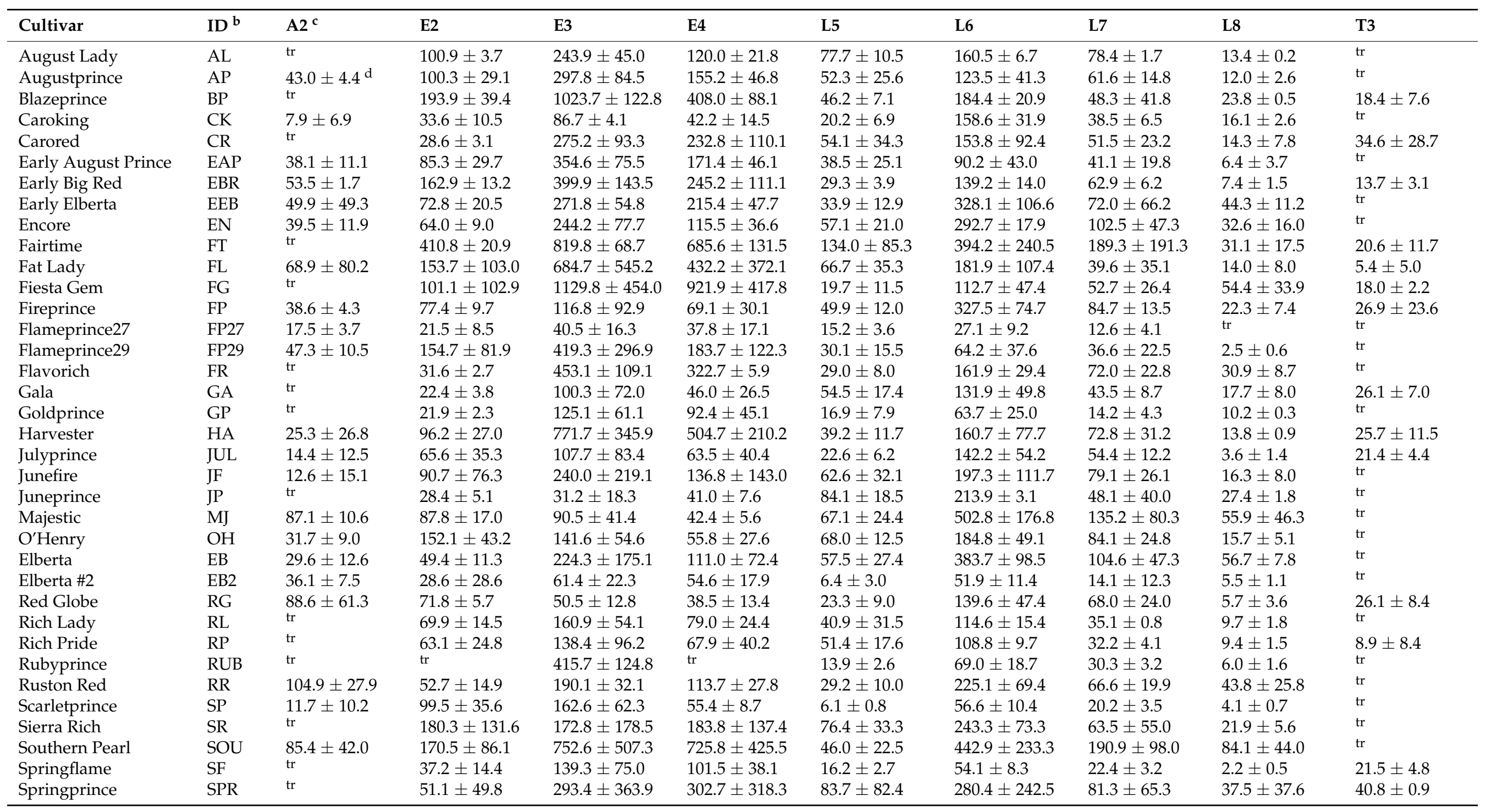


Table 4. Cont.

\begin{tabular}{|c|c|c|c|c|c|c|c|c|c|c|}
\hline Cultivar & ID $^{b}$ & $\mathrm{~A} 2^{\mathrm{c}}$ & E2 & E3 & E4 & L5 & L6 & L7 & L8 & T3 \\
\hline Summerflame & SUM & $\operatorname{tr}$ & $91.8 \pm 53.8$ & $171.1 \pm 140.2$ & $75.5 \pm 59.1$ & $33.7 \pm 14.1$ & $90.1 \pm 39.1$ & $23.8 \pm 21.4$ & $8.2 \pm 4.6$ & $\operatorname{tr}$ \\
\hline Summerflame1 & SUM1 & $\operatorname{tr}$ & $307.1 \pm 192.3$ & $\operatorname{tr}$ & $297.6 \pm 103.1$ & $29.7 \pm 10.8$ & $89.4 \pm 42.6$ & $48.4 \pm 25.9$ & $10.4 \pm 18.0$ & $\operatorname{tr}$ \\
\hline Sureprince & SUR & $\operatorname{tr}$ & $36.5 \pm 0.1$ & $108.6 \pm 31.6$ & $63.7 \pm 61.8$ & $36.6 \pm 15.5$ & $193.8 \pm 81.7$ & $54.9 \pm 21.7$ & $26.1 \pm 6.3$ & $\operatorname{tr}$ \\
\hline Zee Diamond & ZD & $\operatorname{tr}$ & $26.4 \pm 4.4$ & $203.5 \pm 87.0$ & $216.4 \pm 41.9$ & $13.0 \pm 2.9$ & $69.3 \pm 24.0$ & $27.8 \pm 9.8$ & $7.7 \pm 2.7$ & $17.0 \pm 2.4$ \\
\hline Zee Pride & $\mathrm{ZP}$ & $\operatorname{tr}$ & $46.2 \pm 9.5$ & $86.7 \pm 87.1$ & $120.2 \pm 98.5$ & $61.5 \pm 22.6$ & $241.2 \pm 75.2$ & $78.0 \pm 22.5$ & $41.1 \pm 19.1$ & \\
\hline
\end{tabular}

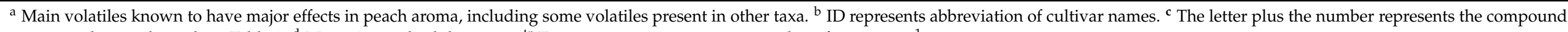
corresponding to the code in Table $1 .{ }^{\mathrm{d}}$ Mean \pm standard deviation. ${ }^{\text {tr }}$ Traces: minimum quantitative value of $<0.4 \mathrm{ng} \cdot \mathrm{g}^{-1}$. 


\subsection{Aldehydes}

Aldehyde content varied across cultivars and across ripening seasons. A total of six aldehydes were detected (Figure 2, Tables 2 and 3). Benzaldehyde (A2) was the most abundant with a content ranging from trace amounts to $104.9 \mathrm{ng} \cdot \mathrm{g}^{-1}$ (Tables 4 and S1). Benzaldehyde is known to act in combination with lactones to shape the basic peach aroma [16]. It is characterized by an "almond" and "burnt sugar" odor as described in the online database Flavornet (http:/ / www.flavornet.org/flavornet.html, accessed on 11 November 2021) and a "fruity" flavor as described by the Good Scents Company (http:/ / www.thegoodscentscompany.com/index.html, accessed on 11 November 2021). The "Ruston Red" cultivar had the highest benzaldehyde content (104.9 ng. ${ }^{-1}$ ) (Table 4). Other cultivars with a high benzaldehyde content (greater than $5 \mathrm{ng} \cdot \mathrm{g}^{-1}[6]$ ) were "Augustprince" (43 ng.g $\left.{ }^{-1}\right)$, “Flameprince29" $\left(47.3 \mathrm{ng} \cdot \mathrm{g}^{-1}\right)$, "Elberta \#2" $\left(49.9 \mathrm{ng} \cdot \mathrm{g}^{-1}\right)$, “Early Big Red" (53.5 ng.g $\left.{ }^{-1}\right)$, “Fat Lady" (68.9 $\left.\mathrm{ng} \cdot \mathrm{g}^{-1}\right)$, “Caroking" (7.9 ng.g $\left.{ }^{-1}\right)$, "Southern Pearl” $\left(85.4 \mathrm{ng} \cdot \mathrm{g}^{-1}\right)$, "Majestic" (87.1 ng.g $\left.{ }^{-1}\right)$, and "Red Globe" (88.6 ng. $\left.{ }^{-1}\right)$ (Table 4). As shown in Figure 2, other abundant aldehydes were nonanal (A4), followed by hexenal (A1), benzeneacetaldehyde (A3), decanal (A5), and dodecanal (A7), in that order. "Fiesta Gem" had the highest of nonanal (A4) with $15.3 \mathrm{ng} \cdot \mathrm{g}^{-1}$. Late-season cultivars had higher benzaldehyde and benzeneacetaldehyde (A3) relative concentrations than early- and mid-season cultivars (Table 3). Benzeneacetaldehyde is characterized by a "green" odor and a "honey" flavor (Good Scents Company database). Hexanal and nonanal relative concentrations were the highest for early-season cultivars in comparison to late- and mid-season cultivars (Table 3). Hexanal is characterized by "grass", "tallow", and "fat" (Flavornet database) odors and "green" odor and flavor (Good Scents Company database). The reported low concentration of aldehydes among all volatiles detected was probably due to all peaches being processed at a fully ripe stage, as aldehydes are characterized by green-grassy notes (Figure 1). They are prominent in immature peaches, and they decrease as the peach ripens $[8,17]$.

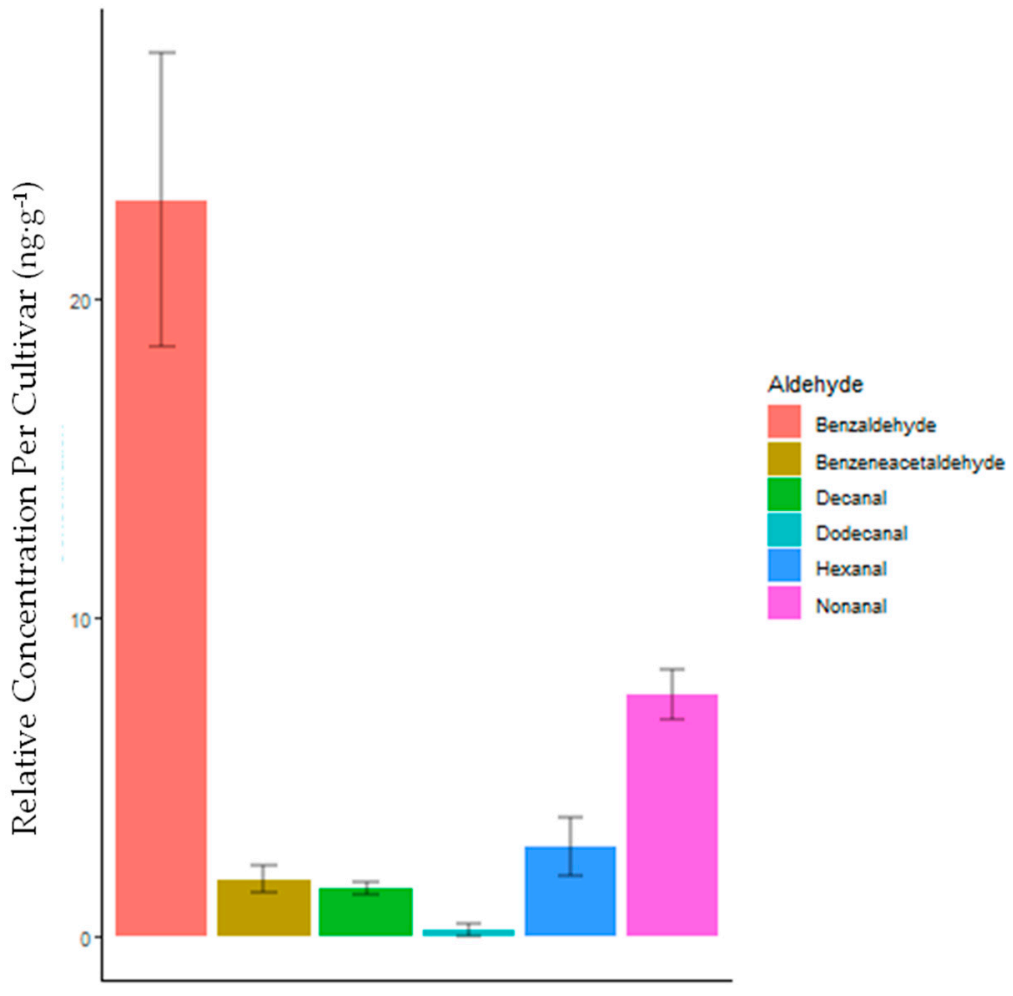

Figure 2. Relative concentration per cultivar (ng. $\mathrm{g}^{-1}$ ) of aldehydes across 42 peach cultivars. Mean values of 3 fruit purée samples per cultivar. Standard error (SE) bars are reported. 


\subsection{Alcohols}

A total of six alcohols were detected: (E)-3-hexen-1-ol (B1), 2-hexen-1-ol, (E)- (B2), hexanol (B3), octanol (B4), 1-nonanol (B5), and 1-undecanol (B6) (Figure 3, Tables 2 and 3). The prominent alcohols were (E)-3-hexen-1-ol (B1), followed by hexanol (B3) and 2-hexen1-ol, (E)- (B2) (Figure 3). Alcohols and aldehydes are also known as C6 compounds and are mostly known to exhibit "grassy flavor" or "unripe aroma". They are prominent in immature peaches, and they decrease as the peach ripens $[8,17]$. In this study, C6 compounds were detected in certain peach cultivars, with some of them having high concentrations (Table 3). "Fiesta Gem" had the highest (E)-3-hexen-1-ol 925.6 (ng.g ${ }^{-1}$ ) among the cultivars (Table S1). Compounds (E)-3-hexen-1-ol and 1-undecanol relative concentrations were the highest for early-season cultivars in comparison to late- and midseason cultivars. (E)-3-Hexen-1-ol is characterized by a "green" odor and 1-undecanol by "waxy", "citrus", and "mandarin" odors (Flavornet and the Good Scents Company databases). 1-Nonanol was the lowest for late-season cultivars in comparison with earlyand mid-season (Table 3). 1-Nonanol is characterized as "fat" and "green" odor (Flavornet database); and "floral" odor and "waxy" flavor (Good Scents Company database). The relative total concentration of alcohols per cultivar were almost triple in early-season cultivars in comparison with the mid- and late-season cultivars (Figure 1). This result needs to be further studied as it may represent differences in odor and flavor possibly associated with fruit development period, and that may influence consumer perception.

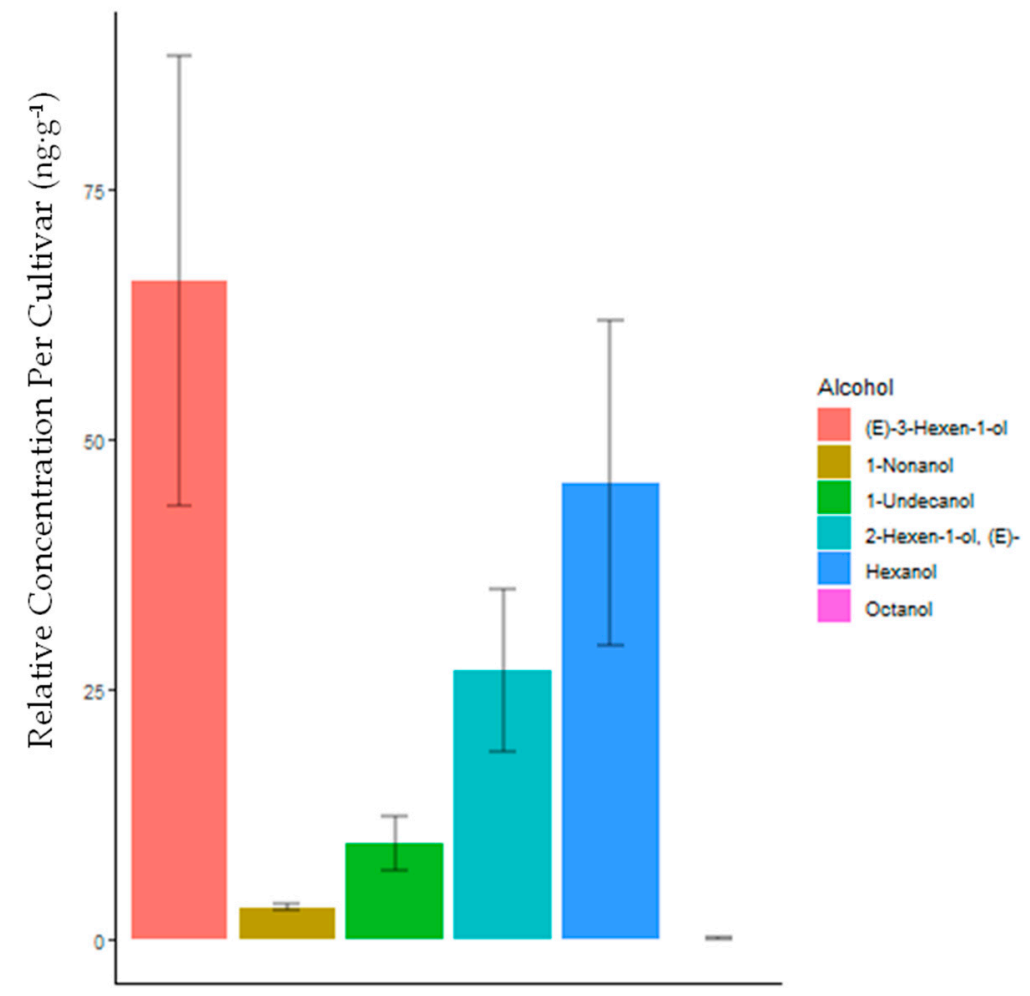

Figure 3. Relative concentration per cultivar (ng. $\mathrm{g}^{-1}$ ) of alcohols in 42 peach cultivars. Mean values of 3 fruit purée samples per cultivar. Standard error (SE) bars are reported.

\subsection{Esters}

Esters were the most-abundant volatiles (Figure 1). This result disagreed with the findings by Wang et al. [6], where esters were the second-most abundant following lactones. This result may support the findings of a previous study, which suggested that if a headspace sampling method is used instead of a vacuum steam distillation, there is the possibility for more esters to be identified [18]. In peach fruit, it has been reported that lactones and esters are known for "fruity" aromas [19]. A total of ten esters were identified 
(Figure 4). Hexyl acetate (E3), 2-hexen-1-ol, acetate, (Z)- (E4), and 3-hexen-1-ol, acetate, (Z)- (E2) were the most-abundant esters, and they contributed over $95 \%$ of the total esters (Figure 4). For the individual cultivars, "Fiesta Gem" had the most-abundant content of hexyl acetate (E3), $1129.8 \mathrm{ng} \cdot \mathrm{g}^{-1}$, followed by "Blazeprince", $1023.7 \mathrm{ng} \cdot \mathrm{g}^{-1}$, and "Fairtime", $819.8 \mathrm{ng} \cdot \mathrm{g}^{-1}$. "Summerflame" had the lowest relative concentration with only traces of hexyl acetate (Tables 4 and S1). Hexyl acetate is characterized by "fruit" and "herb" odors (Flavornet database) and "fruity" flavor (Good Scents Company database). The overall high content of hexyl acetate in this study may influence the "sweet" and "fruity" attributes of peaches [20].

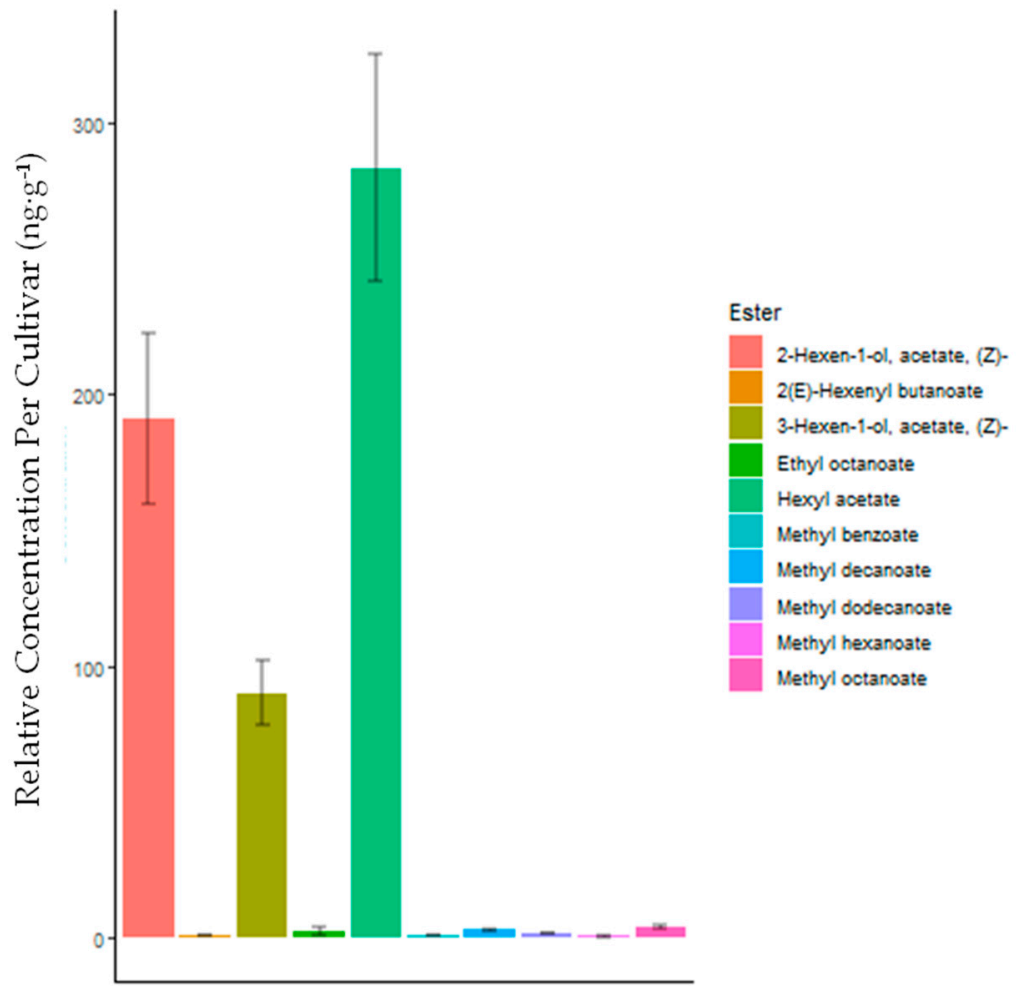

Figure 4. Relative concentration per cultivar $\left(\mathrm{ng} \cdot \mathrm{g}^{-1}\right)$ of esters in 42 peach cultivars. Mean values of 3 fruit purée samples per cultivar. Standard error (SE) bars are reported.

The level of 3-hexen-1-ol, acetate, (Z)- (E2), was abundant in "Fairtime" with $410.8 \mathrm{ng} \cdot \mathrm{g}^{-1}$ followed by "Summerflame" and "Blazeprince" with $307.1 \mathrm{ng} \cdot \mathrm{g}^{-1}$ and $193.9 \mathrm{ng} \cdot \mathrm{g}^{-1}$, respectively (Tables 4 and S1). The relative concentration of compounds 3-hexen-1-ol, acetate, (Z)(E2) and hexyl acetate (E3) were above their odor threshold (13 $\mathrm{ng} \cdot \mathrm{g}^{-1}$ and $2 \mathrm{ng} \cdot \mathrm{g}^{-1}$, respectively), which suggests that they may have an important effect on the overall peach aroma. This result was consistent with previous research, where hexyl acetate and 3-hexen-1-ol, acetate, (Z)- were identified as among the key odorants for the flavor quality of peach fruit [8]. Late-season cultivars had higher 3-hexen-1-ol, acetate, (Z)- (E2) and 2(E)-hexenyl butanoate (E8) relative concentrations than early- and mid-season cultivars (Table 3). Methyl octanoate (E6) relative concentrations were the highest for mid-season cultivars in comparison to lateand early-season cultivars (Table 3). The relative total concentration of esters per cultivar was higher in early-season cultivars in comparison with the mid- and late-season cultivars (Figure 1). 


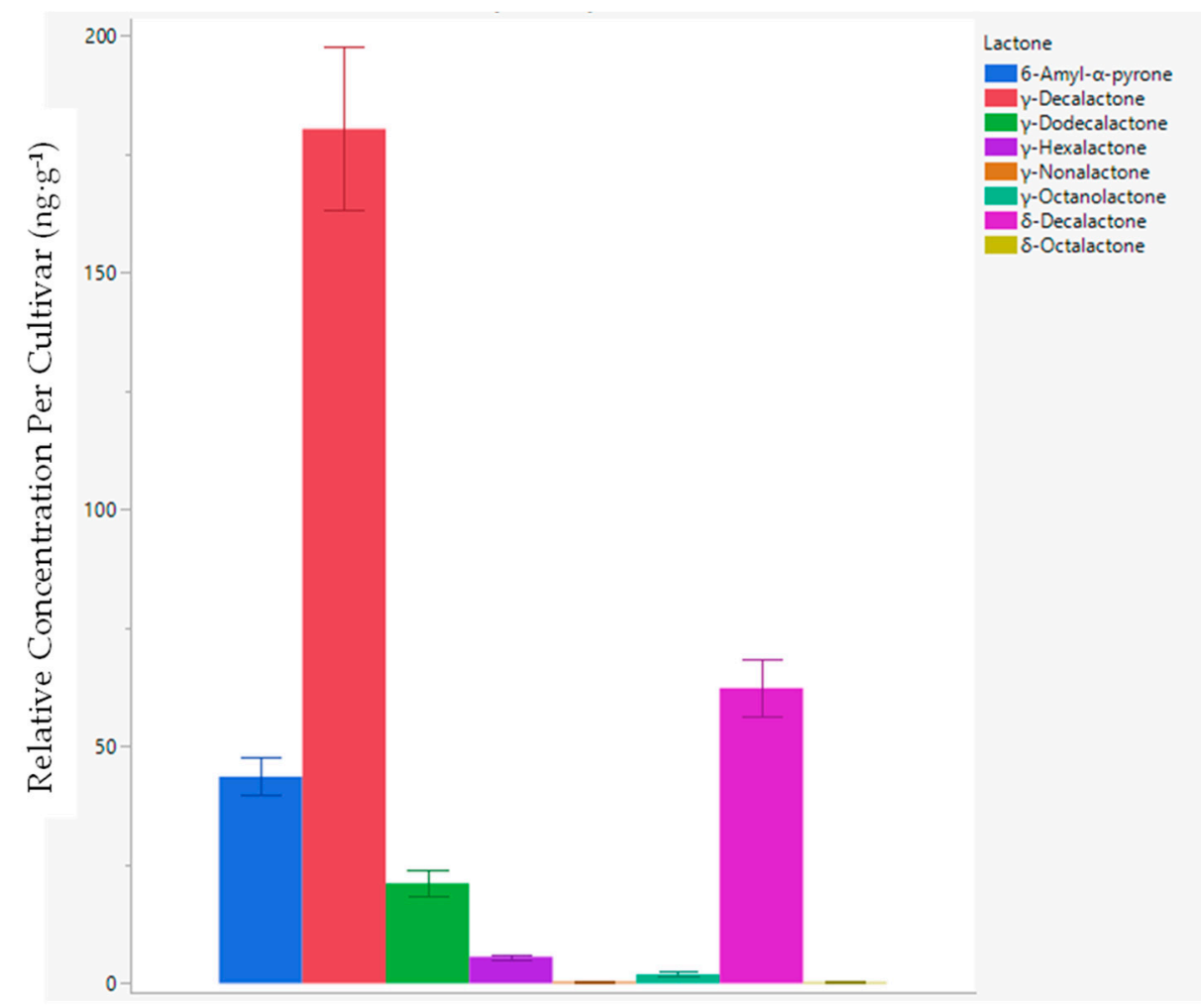

Figure 5. Relative concentration per cultivar (ng. $\mathrm{g}^{-1}$ ) of lactones in 42 peach cultivars. Mean values of 3 fruit purée samples per cultivar. Standard error (SE) bars are reported.

\subsection{Lactones}

Among the 42 cultivars, the most-abundant lactones were $\gamma$-decalactone (L6), $\delta$ decalactone (L7), and 6-amyl- $\alpha$-pyrone (L5) (Figure 5). The top three cultivars with the highest amount of $\gamma$-decalactone (L6) were "Majestic", "Southern Pearl", and "Fairtime" with $502.8 \mathrm{ng} \cdot \mathrm{g}^{-1}, 442.9 \mathrm{ng} \cdot \mathrm{g}^{-1}$, and $394.2 \mathrm{ng} \cdot \mathrm{g}^{-1}$, respectively (Tables 4 and S1). The cultivar with the lowest amount of $\gamma$-decalactone (L6) was "Flameprince27" with $27.1 \mathrm{ng} \cdot \mathrm{g}^{-1} \cdot \gamma$-decalactone is characterized by a "peach" odor (Flavornet dataset) and a "fruity" odor and flavor (Good Scents Company dataset). The second-most-abundant lactone was $\delta$-decalactone (L7) (Tables 4 and S1). "Southern Pearl" had $190.9 \mathrm{ng} \cdot \mathrm{g}^{-1}$, "Fairtime" $189.3 \mathrm{ng} \cdot \mathrm{g}^{-1}$, and "Majestic" $135.2 \mathrm{ng} \cdot \mathrm{g}^{-1}$ of $\delta$-decalactone (L7). $\delta$-decalactone is characterized by a "coconut" odor and flavor (Flavornet and Good Scents Company databases). The third-most-abundant lactone was 6-amyl- $\alpha$-pyrone (L5) with "Fairtime" $134 \mathrm{ng} \cdot \mathrm{g}^{-1}$, "Juneprince" $84.1 \mathrm{ng} \cdot \mathrm{g}^{-1}$, and "Springprince" $83.7 \mathrm{ng} \cdot \mathrm{g}^{-1}$ having the highest amounts among all cultivars evaluated (Tables 4 and S1). Mid-season cultivars were the highest for $\gamma$-hexalactone, $\gamma$-octanolactone, $\delta$-octalactone, and $\gamma$-decalactone compounds in comparison with early- and late-season cultivars (Table 3). Lactones, especially $\gamma$ decalactone (L6) and $\delta$-decalactone (L7), have been described to be a major factor in the production of the characteristic peach-like aroma [6]. However, they do not work in isolation, but rather in combination with terpenes, alcohols, and aldehydes to give peaches their characteristic aroma. This result was consistent with previous studies where $\gamma$-decalactone (L6) and $\delta$-decalactone (L7) were identified among the most-abundant lactones, while $\gamma$-nonalactone (L4) and $\delta$-octalactone (L3) were among the least-abundant lactones [8]. The relative total concentration of lactones per cultivar were higher in mid-season cultivars in comparison with early- and late-season cultivars (Figure 1).

\subsection{Terpenoids}

The dominant terpenoid compound among all cultivars was linalool (T3). Linalool accounted for over $79 \%$ of the total terpenoids (Figure 6) and ranged from traces to $40.8 \mathrm{ng} \cdot \mathrm{g}^{-1}$. 
This result was consistent with previous investigations where linalool was identified to be the most-abundant terpene in nine different peach accessions [8]. Linalool was detected in 15 out of the 42 cultivars that were analyzed. The "fresh floral" and "fruity" attributes of peaches are known to be the result of the contribution from terpenoids [19]. Linalool is characterized by "floral" and "lavender" odors (Flavornet and Good Scents Company databases) and "citrus" flavor (Good Scents Company database). In mature peaches, one of the most abundant compounds is linalool, and its level typically increases as fruit reaches maturity $[4,8]$. In this study, the cultivars with the highest linalool content were "Springprince", followed by "Caroking" and "Fireprince" with $40.8 \mathrm{ng} \cdot \mathrm{g}^{-1}, 34.6 \mathrm{ng} \cdot \mathrm{g}^{-1}$, and $26.9 \mathrm{ng} \cdot \mathrm{g}^{-1}$, respectively (Tables 4 and S1). Early-season cultivars had a higher relative concentration of linalool (T3) and geranyl acetone (T4) in comparison to mid- and late-season cultivars (Table 3). Geranyl acetone is characterized by "magnolia" and "green" odors (Flavornet database) and "floral" odor and flavor (Good Scents Company database).

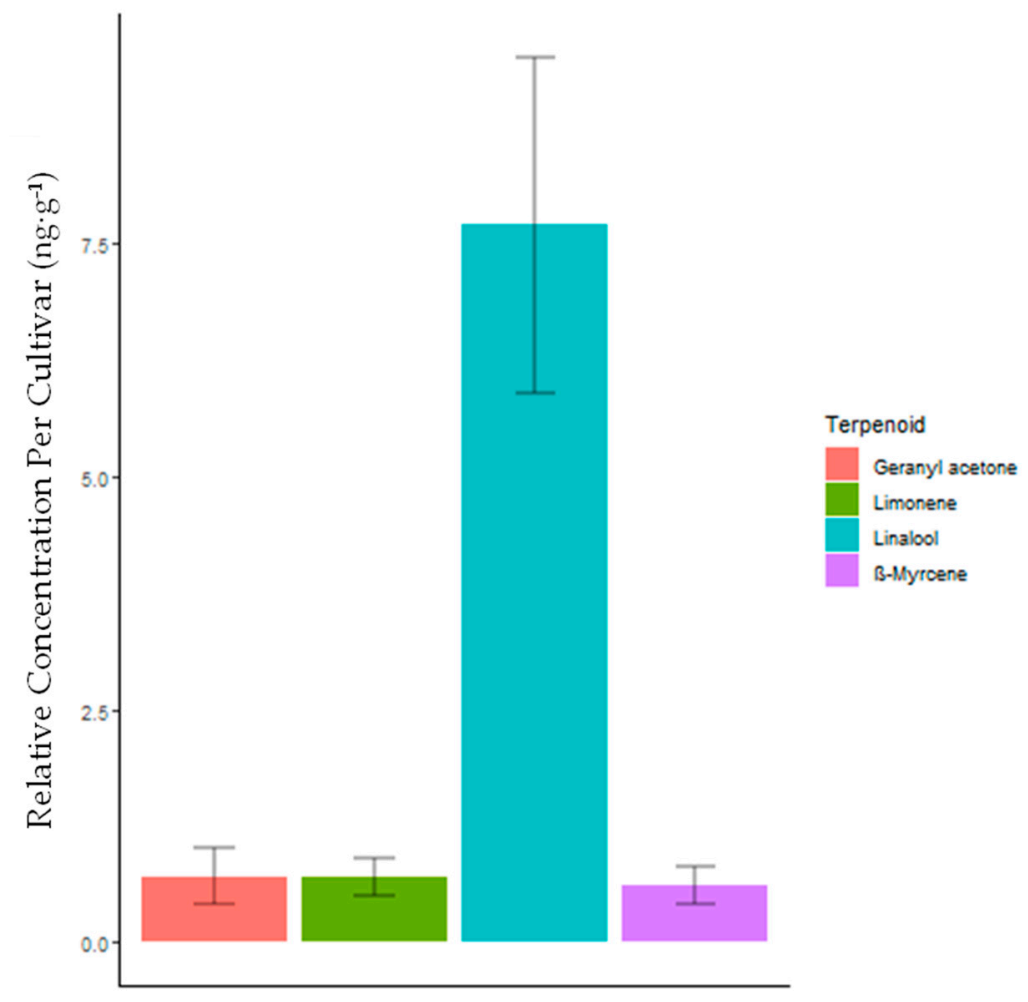

Figure 6. Relative concentration per cultivar (ng. $\mathrm{g}^{-1}$ ) of terpenoids in 42 peach cultivars. Mean values of 3 fruit purée samples per cultivar. Standard error (SE) bars are reported.

Compounds' contribution to aroma does not only depend on their amount, but also on their odor-detection-threshold values [19]. The linalool content in this study was above its odor-threshold levels from the literature $\left(6 \mathrm{ng} \cdot \mathrm{g}^{-1}\right.$ or $\left.6 \mathrm{ppb}\right)$ [21], which may have resulted in a contribution to the peach aroma of the cultivars evaluated. This result was consistent with previous studies where linalool was suggested to contribute to the floral aroma attribute of the samples evaluated [22]. Similar results were also found in the study by Hovart and Chapman [7], where linalool was suggested to be a key odorant of peach after it had an odor-active-value greater than $1(\mathrm{OAV}>1)$.

\subsection{Principal Component Analysis}

The mean concentrations of the various volatile compounds identified were used in a principal component analysis (PCA). From the PCA, the percent cumulative contribution of variance for the first two PCs was $63.06 \%$, providing a good quality projection (Figure 7). 

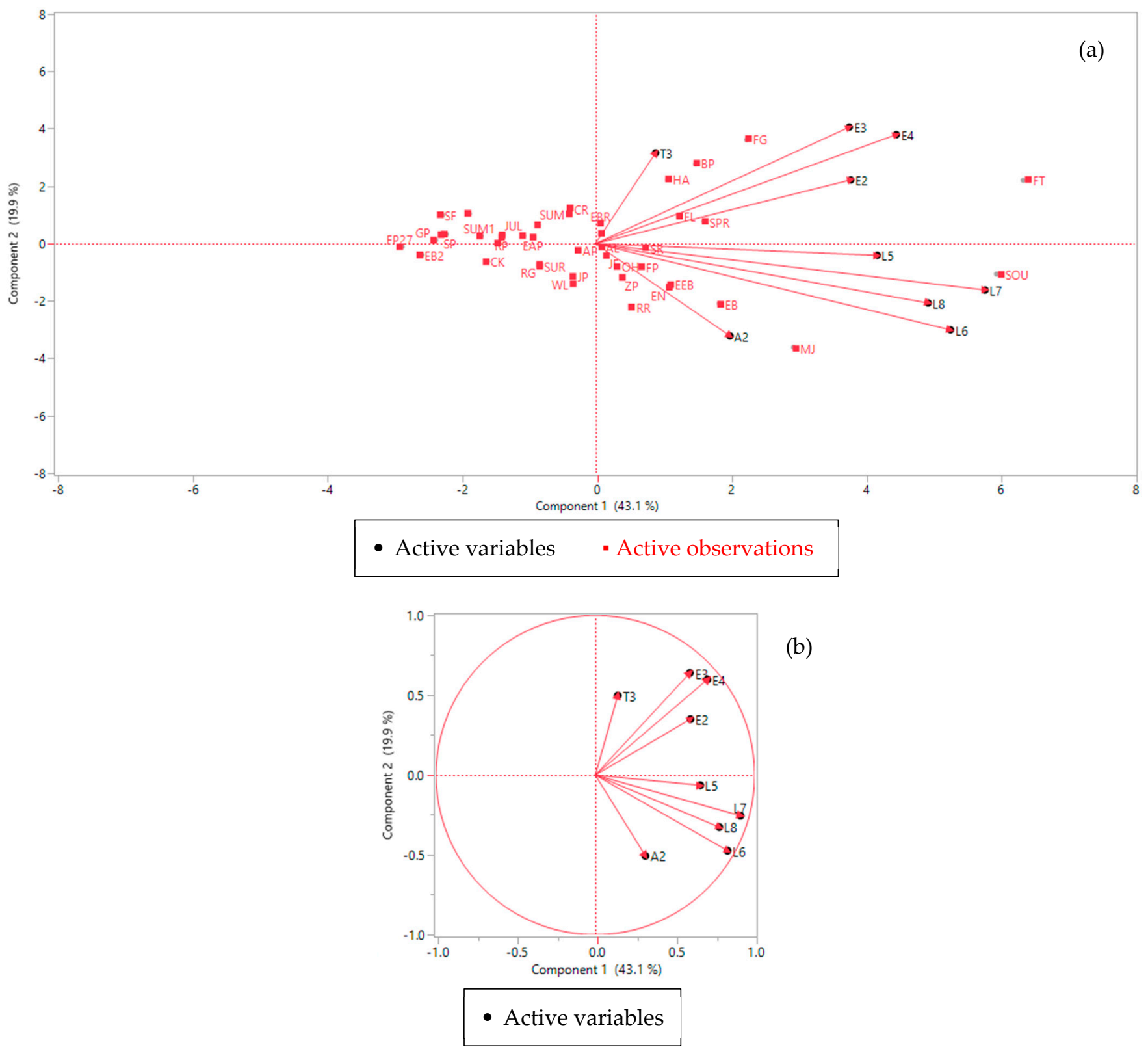

(b)

Figure 7. Principal component analysis. (a) Biplot for the first and second principal components or factors obtained by the contents of the volatile compositions excluding A6 compounds. Cultivar IDs correspond to abbreviations used in Table 4. (b) Score plot of the variables. The letters and numbers represent the volatile compounds detected and correspond to the codes found in Table 2.

From the score plot, the compounds hexyl acetate (E3) and 2-hexen-1-ol, acetate, (Z)(E4) were highly associated with each other. The same was observed for the compounds 6 -amyl- $\alpha$-pyrone (L5), $\gamma$-decalactone (L6), $\delta$-decalactone (L7), and $\gamma$-dodecalactone (L8) (Figure $7 \mathrm{~b}$ ). The extraction of the volatiles was performed on mature peach fruit confirmed by the presence of these compounds, mostly esters and lactones [10,11]. This supports the findings from Spencer et al. [9]. The authors reported higher amounts of esters, lactones, and monoterpenes, such as linalool, in matured peach fruits.

From the PCA biplot (Figure 7a), it can be seen that some of the genotypes are unique with regard to their volatile compositions. "Fiesta Gem" had the highest amount of hexyl acetate (E3) and 2-hexen-1-ol, acetate, (Z)- (E4), followed by "Blazeprince", "Fairtime", and "Harvester". "Majestic" and "Southern Pearl" were also unique in that they had the highest amount of two of the characteristic peach aroma compounds $\gamma$-decalactone (L6) 
and $\delta$-decalactone (L7) (Figure 7a). $\gamma$-decalactone was present in all the cultivars (Table 4) in an amount that was above their odor-threshold levels (11 ng. g ${ }^{-1}$ or $11 \mathrm{ppb}$ [20]) and hence should contribute to peach aroma. In the cultivar "Majestic", which had the highest amount of $\gamma$-decalactones ( $502.8 \mathrm{ng}^{\circ} \mathrm{g}^{-1}$ ), the level was approximately 45 -fold higher than the odorthreshold value. In these 42 cultivars, the benzaldehyde content (Table 4 ) was lower than its odor-threshold values (350 $\mathrm{ng} \cdot \mathrm{g}^{-1}$ or $350 \mathrm{ppb}$, [21]) and thus would contribute little to the peach aroma. Similar results were reported with $\delta$-decalactone since its levels were much lower than its odor-threshold values (400 $\mathrm{ng} \cdot \mathrm{g}^{-1}$ or $400 \mathrm{ppb}$ ) [20,21].

\subsection{Cluster Analysis}

Hierarchical cluster analysis (HCA) of the forty-two peach cultivars was performed using the nine volatile compounds characterized as peach aroma volatiles from the previous literature, as listed in Table 4. The Euclidean method was used for the distance calculation for the cluster analysis. The forty-two peach cultivars can be grouped into two different clusters (Figure 8). Cluster 1 was made up of 37 peach cultivars. Cluster 2 was made up of 5 peach cultivars. From the dendrogram, the genotypes in Cluster 2 are further apart than the genotypes found in Cluster 1. The "Fairtime" and "Southern Pearl" cultivars both were found to have the highest levels for multiple volatiles detected in this study (Table S1). The results of this cladogram may represent the complexity of their flavor profile, with Cluster 1 representing cultivars with unique flavor and aroma characteristics.

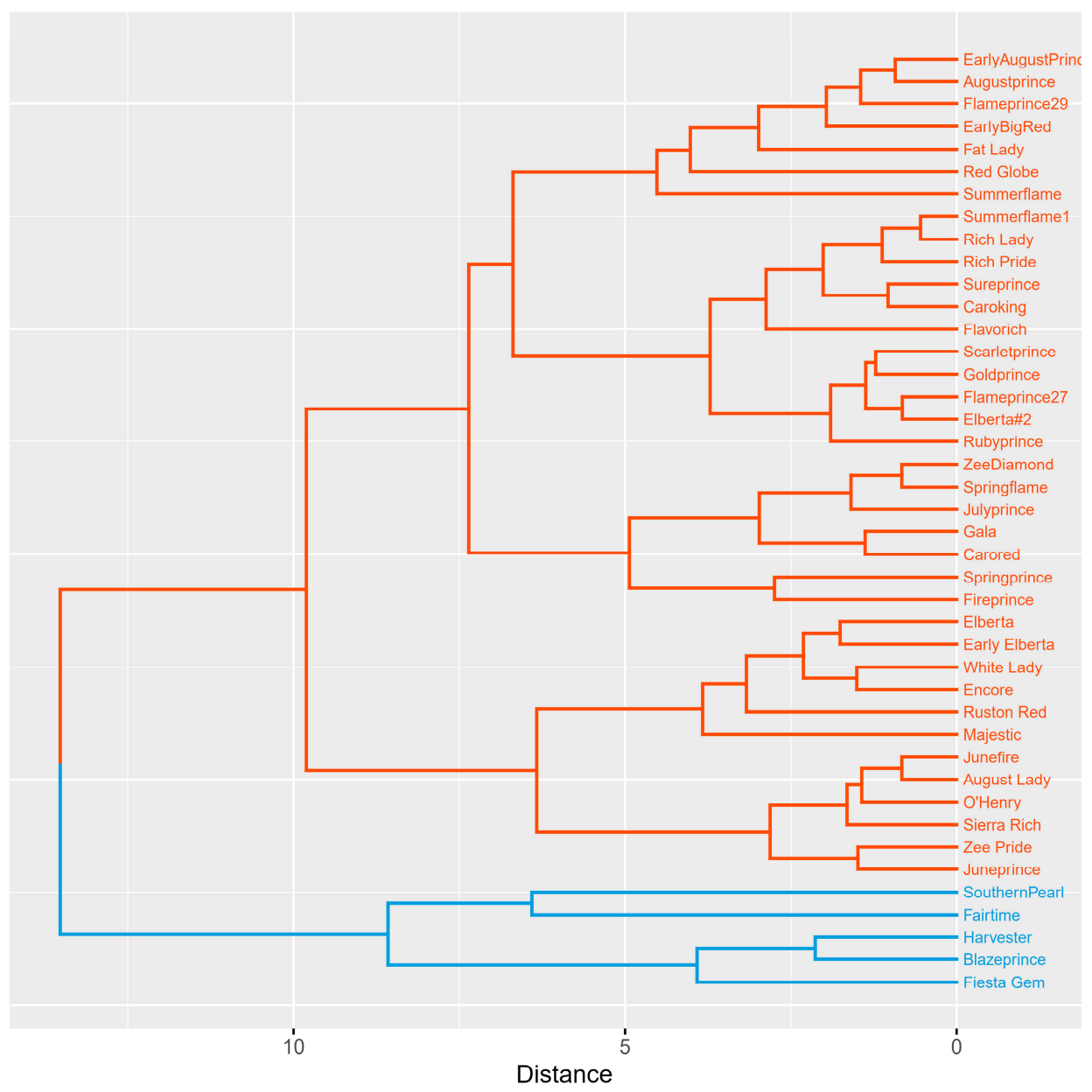

Figure 8. Hierarchical agglomerative cluster analysis based on a similarity matrix using the Euclidean method of 42 peach cultivars based on 9 major volatile compounds that characterize peach aroma. 
The peach characteristic aroma volatiles such as benzaldehyde, linalool, $\gamma$-decalactone, and $\delta$-decalactone have been reported in the literature to increase their levels during maturation $[3,8]$. Since all the cultivars in this study were processed fully ripened, these compounds were compared across the three harvest seasons (early, mid, and late) to determine which harvest season had more of these volatiles (Figure 9). It could be seen that overall, mid- and late-season peaches had significantly higher benzaldehyde than the early-season cultivars. For linalool and $\delta$-decalactone, there was no significant difference between the three harvest seasons. Mid-season cultivars overall were significantly higher than both early- and late-season cultivars for $\gamma$-decalactone. Since there are not many differences among the three seasons with only a few exceptions, it could be suggested that peach aroma/flavor may be attributed by the interaction of multiple factors such as fruit growth characteristics, environmental factors, genetic components, and others.

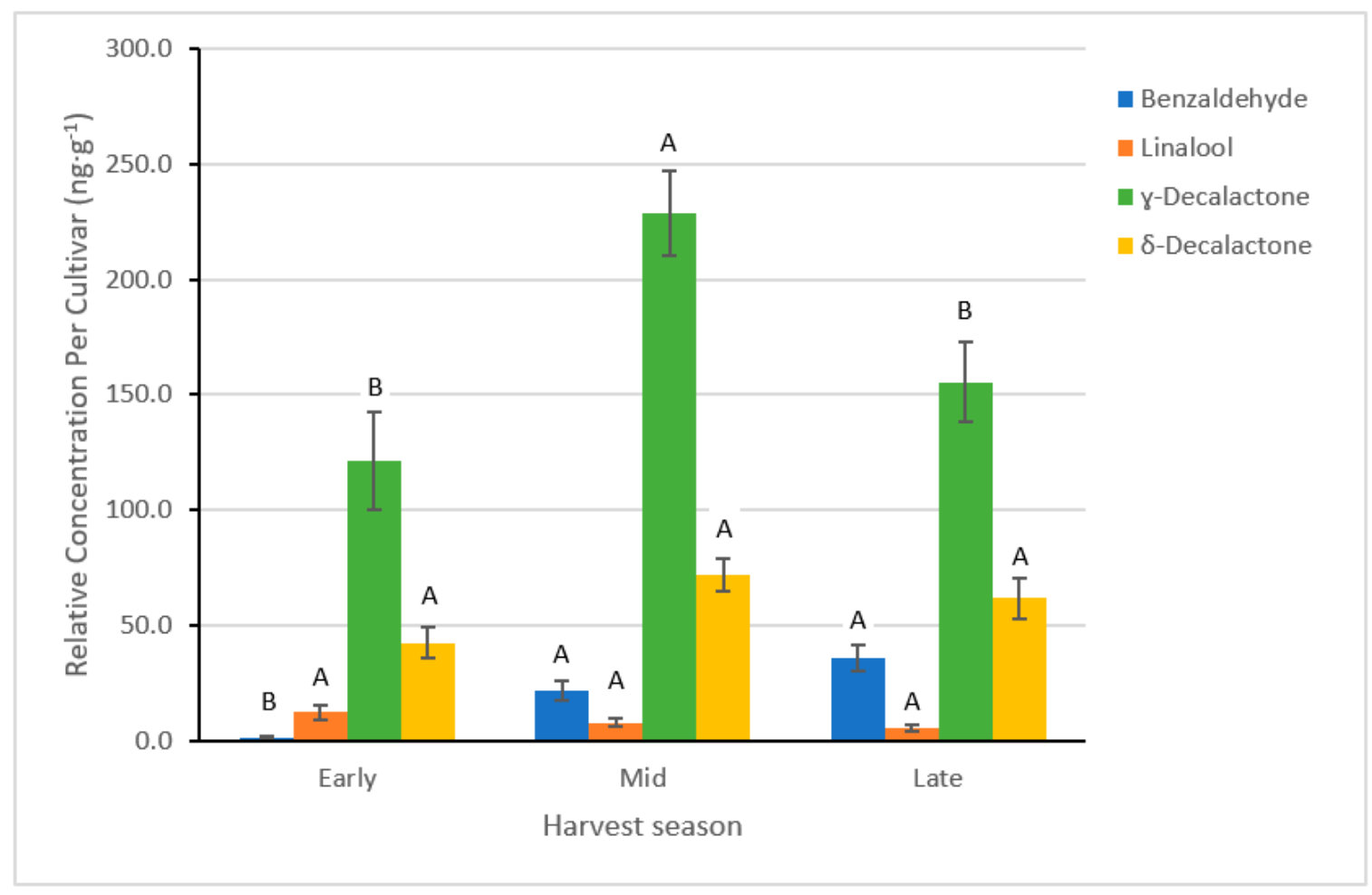

Figure 9. Overall comparison of early-, mid-, and late-season peach cultivars for the four major peach aroma volatile compounds as reported in previous literature. Bars represent the relative concentration per cultivar within each season. Mean comparisons were made within a compound with different letters indicating significant difference among ripening seasons using the LSD test at $p<0.05$.

\section{Conclusions}

This study was able to identify 36 volatile compounds with all showing significant differences across the 42 cultivars analyzed. The identified volatiles consisted of aldehydes, alcohols, esters, lactones, terpenes, a carboxylic acid, and a ketone. The abundance of esters such as hexyl acetate and 3-hexen-1-ol, acetate, (Z)- and lactones such as $\gamma$-decalactone and $\delta$-decalactone suggest that these compounds might constitute part of the "fruity" aromas characteristic of a peach fruit, which is in agreement with previous studies [8,19]. Early-season cultivars were characterized by a higher relative total concentration of alcohol and esters. On the contrary, mid-season cultivars were characterized by a higher relative total concentration of lactones. These aroma and flavor differences may be attributed to fruit growth characteristics, environmental factors, and genetic components, among others. Future research with mature and immature peach fruit from different ripening seasons 
would help elucidate which compounds are characteristic of different seasons and fruit developmental stages.

Supplementary Materials: The following are available online at https://www.mdpi.com/article/ 10.3390/horticulturae7120516/s1, Table S1. Mean values for volatile compounds (ng. $\mathrm{g}^{-1}$ ) detected in 42 peach cultivars grown in Georgia, United States of America in 2016.

Author Contributions: Conceptualization, K.A. and D.J.C.; formal analysis, J.M., D.J.C. and K.A.; investigation, C.E.B., S.W., K.A. and D.J.C.; resources, R.A.I.; writing-original draft preparation, J.M. and D.J.C.; writing—review and editing, R.A.I., D.J.C. and K.A.; supervision, D.J.C.; funding acquisition, D.J.C. All authors have read and agreed to the published version of the manuscript.

Funding: This research was funded by the Georgia Agricultural Commission for Peaches, The Georgia Peach Council, Hatch Project GEO00766, and the University Of Georgia.

Institutional Review Board Statement: Not applicable.

Informed Consent Statement: Not applicable.

Data Availability Statement: Data is contained within the article or Supplementary Materials.

Acknowledgments: The authors would like to thank Pearson Farms for the donations of the produce during the length of this project, as well as the technical help at the Department of Horticulture and the Department of Food Science and Technology.

Conflicts of Interest: The authors declare no conflict of interest.

\section{References}

1. Causse, M.; Stevens, R.; Amor, B.B.; Faurobert, M.; Muños, S. Breeding for Fruit Quality in Tomato. In Breeding Fruit Quality; Jenks, M.A., Bebeli, P.J., Eds.; Wiley: New York, NY, USA, 2011; pp. 279-305. [CrossRef]

2. Bruhn, C.M. Consumer and Retailer Satistfaction with the Quality and Size of California Peaches and Nectarines. J. Food Qual. 1994, 18, 241-256. [CrossRef]

3. Derail, C.; Hofmann, T.; Schieberle, P. Differences in key odorants of handmade juice of yellow-flesh peaches (Prunus persica L.) Induced by the workup procedure. J. Agric. Food Chem. 1999, 47, 4742-4745. [CrossRef] [PubMed]

4. Chapman, G.W.; Horvat, R.J.; Forbus, W.R. Physical and Chemical Changes During the Maturation of Peaches (cv. Majestic). J. Agric. Food Chem. 1991, 39, 867-870. [CrossRef]

5. Aubert, C.; Günata, Z.; Ambid, C.; Baumes, R. Changes in physicochemical characteristics and volatile constituents of yellow- and white-fleshed nectarines during maturation and artificial ripening. J. Agric. Food Chem. 2003, 51, 3083-3091. [CrossRef] [PubMed]

6. Wang, Y.; Yang, C.; Li, S.; Yang, L.; Wang, Y.; Zhao, J.; Jiang, Q. Volatile characteristics of 50 peaches and nectarines evaluated by HP-SPME with GC-MS. Food Chem. 2009, 116, 356-364. [CrossRef]

7. Horvat, R.J.; Chapman, G.W. Comparison of Volatile Compounds from Peach Fruit and Leaves (cv. Monroe) during Maturation. J. Agric. Food Chem. 1990, 38, 1442-1444. [CrossRef]

8. Eduardo, I.; Chietera, G.; Bassi, D.; Rossini, L.; Vecchietti, A. Identification of key odor volatile compounds in the essential oil of nine peach accessions. J. Sci. Food Agric. 2010, 90, 1146-1154. [CrossRef] [PubMed]

9. Spencer, M.D.; Pangborn, R.M.; Jennings, W.G. Gas Chromatographic and Sensory Analysis of Volatiles from Cling Peaches. J. Agric. Food Chem. 1978, 26, 725-732. [CrossRef]

10. Do, J.Y.; Salunkhe, D.K.; Olson, L.E. Isolation, Identification and Comparison of the Volatiles of Peach Fruit as Related to Harvest Maturity and Artificial Ripening. J. Food Sci. 1969, 34, 618-621. [CrossRef]

11. Bacvonkralj, M.; Jug, T.; Komel, E.; Fajt, N.; Jarni, K.; Živković, J.; Mujić, I.; Trutić, N. Effects of ripening degree and sample preparation on peach aroma profile characterization by headspace solid-phase microextraction. Turkish J. Agric. For. 2014, 38, 676-687. [CrossRef]

12. Jia, H.J.; Araki, A.; Okamoto, G. Influence of fruit bagging on aroma volatiles and skin coloration of "Hakuho" peach (Prunus persica Batsch). Postharvest Biol. Technol. 2005, 35, 61-68. [CrossRef]

13. Robertson, J.A.; Horvat, R.J.; Lyon, B.G.; Meredith, F.I.; Senter, S.D.; Okie, W.R. Comparison of Quality Characteristics of Selected Yellow-and White-fleshed Peach Cultivars. J. Food Sci. 1990, 55, 1308-1311. [CrossRef]

14. Blaauw, B.; Brannen, P.; Lockwood, D.; Schhnabel, G.; Ritchie, D. Southeastern Peach, Nectarine and Plum Pest Management and Culture Guide; Bulletin 1171; University of Georgia Cooperative Extension: Athens, GA, USA, 2018; pp. 1-78.

15. Belisle, C.; Phan, U.T.X.; Adhikari, K.; Chavez, D.J. A fruit quality survey of peach cultivars grown in the Southeastern United States. Horttechnology 2018, 28, 189-201. [CrossRef]

16. Montero-Prado, P.; Bentayeb, K.; Nerín, C. Pattern recognition of peach cultivars (Prunus persica L.) from their volatile components. Food Chem. 2013, 138, 724-731. [CrossRef] [PubMed] 
17. Kakiuchi, N.; Ohmiya, A. Changes in the Composition and Content of Volatile Constituents in Peach Fruits in Relation to Maturity at Harvest and Artificial Ripening. J. Jpn. Soc. Hort. Sci. 1991, 60, 209-216. [CrossRef]

18. Takeoka, G.R.; Jennings, W.; Flath, R.A.; Güntert, M. Nectarine volatiles: Vacuum steam distillation versus headspace sampling. J. Agric. Food Chem. 1988, 36, 553-560. [CrossRef]

19. El Hadi, M.A.M.; Zhang, F.J.; Wu, F.F.; Zhou, C.H.; Tao, J. Advances in fruit aroma volatile research. Molecules 2013, 18, 8200-8229. [CrossRef]

20. Bononi, M.; Bassi, D.; Tateo, F. "Flavor Intensity" evaluation of two peach fruit accessions and their four offspring at unripe and ripe stages by HS-SPME-GC/MS. Food Public Health 2012, 2, 301-308. [CrossRef]

21. Engel, K.H.; Flath, R.A.; Buttery, R.G.; Mon, T.R.; Teranishi, R.; Ramming, D.W. Investigation of volatile constituents in nectarines. 1. Analytical and sensory characterization of aroma components in some nectarine cultivars. J. Agric. Food Chem. 1988, 36, 549-553. [CrossRef]

22. Zhu, J.C.; Chen, F.; Wang, L.Y.; Niu, Y.W.; Yu, D.; Shu, C.; Chen, H.X.; Wang, H.L.; Xiao, Z.B. Comparison of Aroma-Active Volatiles in Oolong Tea Infusions Using GC-Olfactometry, GC-FPD, and GC-MS. J. Agric. Food Chem. 2015, 63, 7499-7510. [CrossRef] [PubMed] 